\title{
Effect of Drought Stress on Tomato cv. Bombino
}

Sher Hassan Khan ${ }^{1 *}$, Arsalan Khan ${ }^{1}$, Uzma Litaf ${ }^{1}$, Abdul Sattar Shah², Muhammad Ali Khan ${ }^{1}$, Muhammad Bilal ${ }^{2}$ and Muhammad Usman Ali ${ }^{3}$

${ }^{1}$ Agriculture Research Institute, Tarnab, Peshawar, Pakistan

${ }^{2}$ Department of Food Science and Technology, Faculty of Agriculture, The University of Swabi, KPK, Pakistan

${ }^{3}$ Department of Food Science and Technology, Faculty of Nutritional Sciences, NWFP Agriculture University Peshawar, Pakistan

\begin{abstract}
To study "the effect of drought stress on Tomato (Lycopersicon esculentum) Cv. Bombino" an experiment was conducted at Institute of Biotechnology and Genetic Engineering, Agricultural University Peshawar. Tomato plants were grown in green house under two different conditions of water availability i.e.- controlled and drought. The parameters studied were relative water content $(\%)$, proline content ( $\mu$ moles) and relative growth rate $\left(\right.$ week $\left.^{-1}\right)$. Drought stress has significant effect on all parameters studied. The relative water content of plant body decline during drought due to less water availability. In controlled environment, the mean value of relative water content was 89.28 while that observed in drought condition was 87.73 . Proline was observed on rise due to continuous decrease in water quantity in cell sap. The value of proline content is $4.4 \mu$ moles $\mathrm{g}^{-1}$ fresh weight in controlled condition whereas that the plants in drought condition had $5.8 \mu$ moles $\mathrm{g}^{-1}$ fresh weight. Due to less water, photosynthesis was negatively affected which resulted in less energy production and finally low growth. In controlled condition the relative growth rate week ${ }^{-1}$ on fresh weight was $1.37 \mathrm{gm}$ whereas that of plant in drought condition was $0.57 \mathrm{gm}$.
\end{abstract}

Keywords: Melon; Shelling; Seed damage; Performance evaluation; Efficiency

\section{Introduction}

The tomato (Lycopersicon esculentum) belongs to the solanaceae (night shade) family. It is native to tropical America where its indigenous name was tomati. From Mexico the tomato was taken to Europe and then to Asia. An important vegetable crop, it is grown in most home gardens and by market gardeners and truck farmers. It is also produced by forcing in green houses. It can be eaten either fresh or processed into many different products. It plays a vital role in maintaining health and vigor. Tomatoes are very helpful in healing wounds because of the antibiotic properties found in the ripe fruit. It is a good source of vitamins A, B and C. It is widely used in salad as well as for culinary purposes. Tomato gain popularity very rapidly and attain the status of widely consumed. Although tomato is a tender perennial crop, which is susceptible to frost as well as high temperature but it is being grown in a variety of climatic conditions [1].

In Pakistan tomato is grown over an area of 24,144 hectares annually, which produces $2,75,241$ tons of tomato. KPK is the major producing region where it is grown on an area of 4230 hectares with a total production of about 51,062 tons annually. In Peshawar valley, quite a sizeable area of 944 acres is put under tomato cultivation with a production of 2.978 thousand tones.

In nature, water is usually the most limiting factor for plant growth. If plants do not receive adequate rainfall or irrigation, the resulting drought stress can reduce growth more than all other environmental stresses combined. A plant responds to a lack of water by halting growth and reducing photosynthesis and other plant processes in order to reduce water use. As water loss progresses, leaves of some species may appear to change color usually to blue-green. Foliage begins to wilt and, if the plant is not irrigated, leaves will fall off and the plant will eventually die.

Drought symptoms resemble salt stress because high concentrations of salts in the root zone cause water loss from roots because of osmotic effect. Close examination of environmental and cultural conditions should help identify the specific problem.

Aside from the moisture content of the soil, environmental conditions of high light intensity, high temperature, low relative humidity and high wind speed will significantly increase plant water loss. The prior environment of a plant also can influence the development of drought stress. A plant that has been drought stressed previously and has recovered may become more drought resistant. Also, a plant that was well-watered prior to drought will usually survive drought better than a continuously drought-stressed plant.

Drought and salinity are already widespread in many regions, and are expected to cause serious salinization of more than $50 \%$ of all arable lands by the year 2050 [2]. In a world where population growth exceeds food supply, agricultural and plant biotechnologies aimed at overcoming sever environmental stresses need to be fully implemented.

Drought is by far the most important environmental stress in agriculture and many efforts have been made to improve crop productivity under water - limiting condition. While natural selection has favored mechanisms for adaptation and survival, breeding activity has directed selection towards increasing the economic yield of cultivated species. More than 80 years of breeding activities have led to some yield increase in drought environment for many crop plants. Meanwhile, fundamental research has provided significant gains in the understanding of the physiological and molecular responses of plant to water deficit, but there is still a large gap between yield in optimal and stress conditions. Minimizing the 'yield gap' and increasing yield stability under different stress conditions are of strategic importance in guaranteeing food for the future.

So, in this connection the present research was conducted in order to achieve the following objectives.

*Corresonding author: Sher Hassan khan, Agriculture Research Institute, Tarnab, Peshawar, Pakistan, E-mail: sherhassan_khan@yahoo.com

Received February 05, 2015; Accepted May 25, 2015; Published June 01, 2015

Citation: Khan SH, Khan A, Litaf U, Shah AS, Khan MA, et al. (2015) Effect of Drought Stress on Tomato cv. Bombino. J Food Process Technol 6: 465. doi:10.4172/21577110.1000465

Copyright: $\odot 2015 \mathrm{Khan}$ SH, et al. This is an open-access article distributed under the terms of the Creative Commons Attribution License, which permits unrestricted use, distribution, and reproduction in any medium, provided the original author and source are credited. 
1. To study the changes in various physiological and morphological parameters of tomato plant under stress condition.

2. To observe the suitability of tomato $\mathrm{cv}$. Bombino to drought condition.

\section{Review of Literature}

Literature shows various types of experiments have been conducted exhibiting the response of tomato plants to drought stress conditions. Some examples are given below.

Liming et al. [3] stated that although none of the receptors for cold, drought, salinity or the stress, hormone abscisic acid in plants is determined to certainty, current knowledge indicate that receptor like protein kinases, two- component histidine kinases, as well as G-protein-associated receptors may represent the potential sensors of these signals. For example, the expression of histone linker genes in Arabidopsis and in tomato was found to be induced by drought stress and ABA. Alternations in cold acclimation, low-temperature sensitivity and freezing tolerance can be used for screening mutation by scoring visible damages as well as freezing-induce electrolyte leakage.

Leperen et al. [4] studied the distribution of xylem hydraulic resistance in fruiting truss of tomato influenced by water stress. In this study xylem hydraulic resistances of peduncles (truss stalk), pedicels (fruit stalk) and the future abscission zone (AZ) halfway along the pedicel of tomato (Lycopersicon esculentum L.) plants were directly measured at different stages of fruit development, in plants grown under two levels of water availability in the root environment. They noted that the largest resistances were measured in the AZ where most individual vessels ended. Plants grown at low water availability in the root environment had xylem with higher hydraulic resistances in the peduncle and pedicel segments on both sides of the AZ, while the largest increase in hydraulic resistance was measured in the AZ. During fruit development hydraulic resistances in peduncle and pedicel segments decreased on both sides of the AZ, but tended to increase in the AZ. The overall xylem hydraulic resistance between the shoot and fruit tended to increase with fruit development because of the dominating role of the hydraulic resistance in the AZ.

Tokihiko et al. [5] studied that the toxicity of proline (Pro) to plant growth has raised questions despite its protective functions in response to environmental stresses. To evaluate Pro toxicity, they isolated an Arabidopsis T-DNA-tagged mutant, pdh that had a defect in Pro dehydrogenase (AtProDH), which catalyzes the first step of Pro catabolism. The pdh mutant showed hypersensitivity to exogenous application of $<=10 \mathrm{mM} \mathrm{L}$-Pro, at which wild-type plants grew normally. They also suggested that AtProDH is the only enzyme acting as a functional ProDH in Arabidopsis.

Gabriella et al. [6] studied the histone-like protein H1-S and the response of tomato leaves to water deficit. They study the droughtinduced linker histone, H1-S of tomato. They selected three independent H1- antisense tomato mutants, for their inability to accumulate H1-S in response to water stress. These mutants have been characterized at the physiological and morphological levels. They observe that histone H1-S antisense transgenic plants developed normally indicating that H1-S does not play an important role in the basal functions of tomato development. No differences were detected in chromatin organization, excluding a structural role for H1-S in chromatin organization.

Doan and Maurel [7] noted that plants have to adjust their water balance not only in response to very challenging environmental conditions such as drought, salinity and cold but also to changes in light, nutrient deficiency or soil acidity. These mechanisms include the control of aquaporin gene transcription and protein abundance, stimulus-induced aquaporin subcellular relocalization, and channel gating by reversible phosphorylation or by intracellular protons.

Hatem et al. [8] analyzed the physiological responses with a study on changes in proline content. Effects of different level of water stress on leaf water potential, stomatal resistance, Protein and chlorophyll content and certain Anti-oxidative enzymes in tomato plants were determined.

Nayyar et al. [9] examined leaf samples for electrolyte leakage (EL) 2, 3, 5-triphenyl tetrazolium chloride (TTC), reduction assay relative leaf water content and chlorophyll. Endogenous content of PA revealed that both the species varied distinctively with respect to their type, amount and rate of accumulation.

Zhizhong et al. [10] performed a detailed analysis on two allelic Arabidopsis mutants, leaf wilting 2-1 and leaf wilting 2-2 (lew21 and lew2-2), these were isolated in a screen for plants with altered drought stress responses. The mutants were more tolerant to drought stress as well as to $\mathrm{NaCl}$, mannitol and other osmotic stresses. Lew2 mutant plants accumulated more abscisic acid (ABA), proline and soluble sugars than the wild type. The expression of a stress-inducible marker gene RD29A, a proline synthesis-related gene P5CS (pyroline5-carboxylate synthase) and an ABA synthesis-related gene SDR1 (alcohol dehydrogenase/reductase) were higher in lew2 than in the wild type. Results suggested that cellulose synthesis is important for drought and osmotic stress responses including drought induction of gene expression.

Paul et al. [11] studied that plants respond to reduced water availability (low water potential) include both ABA-ABA in low water potential-induced Pro accumulation and osmotic adjustment in seedlings of Arabidopsis thaliana. Low water potential-induced Pro accumulation required wild-type levels of $\mathrm{ABA}$, as well as a change in ABA sensitivity or ABA- independent events. He also observed that abi1-1 and abi2-1 had increased ABA accumulation. The involvement of these loci in feedback regulation of $A B A$ accumulation may occur through an effect on ABA catabolism or conjugation.

Achuo et al. [12] studied the effects of drought, salt stress and $\mathrm{ABA}$ on the interaction of tomato (Lycopersicon esculentum) with the biotrophic fungus Oidium neolycopersici and the necrotrophic fungus Botrytis cinerea. He observed that drought stress resulted in a twofold increase in endogenous $\mathrm{ABA}$ as well as a $50 \%$ reduction in $B$. cinerea infection and a significant suppression of $O$. neolycopersici on tomato cv. Moneymaker. They concluded that, in tomato, drought and salt stress stimulate different, but possibly overlapping, pathogen-defence pathways which may not necessarily involve ABA. They also reported that basal endogenous $A B A$ levels suppress the resistance of tomato to $O$. neolycopersici and $B$. cinerea, but an ABA increase above the basal level, resulting from exogenous application, does not increase susceptibility to these pathogens.

Dhananjay et al. [13] increased leaf phosphorus (P) concentration that improved the water-use efficiency (WUE) and drought tolerance of regularly defoliated white clover plants by decreasing the rate of daily transpiration per unit leaf area in dry soil. The improved control of transpiration in the high-P plants was associated with an increased individual leaf area and WUE that apparently resulted from net photosynthetic assimilation rate being reduced less than the reductions in the transpiration. On the other hand, greater transpiration from low-P 
plants was associated with poor stomatal control of transpirational loss of water, less $\mathrm{ABA}$ in the leaves when exposed to dry soil, and thicker and smaller leaf size compared with high -P leaves.

Hassine et al. [14] studied that an inland and a coastal population of the Mediterranean xero-halophyte species Atriplex halimus L. differ in their ability to accumulate proline and glycinebetaine in response to salinity and water stress. Soil salinity and drought compromise water uptake and lead to osmotic adjustment in xero-halophyte plant species. Plants from Sbikha (non saline semi arid area) were more resistant to water stress and displayed a higher rate of proline accumulation. Proline accumulated as early as $24 \mathrm{~h}$ after stress imposition and such accumulation was reversible. Exogenous application of proline $(1 \mathrm{mM})$ improved the level of drought resistance in Monastir (plants originated from salt affected coastal site) plants through a decrease in oxidative stress quantified by the malondialdehyde concentration.

Cristina et al. [15] reported that arabidopsis MSI1 is required for negative regulation of the response to drought stress. Arabidopsis MSI1 had fundamental functions in plant development. In order to uncover additional functions of MSI1, they performed transcriptional profiling of wild-type and plants with highly reduced MSI1 levels (msil-cs). Surprisingly, the known functions of MSI1 could only account for a minor part of the transcriptional changes in msil-cs plants.MSI1 is a subunit of Polycomb group protein complexes and Chromatin assembly factor 1 , and it interacts with the Retinoblastoma-related protein $1 . \mathrm{He}$ observed that up-regulation of a subset of ABA-responsive genes elicit the response to drought and salt stress.

Mirakhori et al. [16] studied drought stress and methanol on yield and yield components of soybean in field experiments with factorial experiment in the form of a randomized complete block design with three replication in field. First factor were sprayed aqueous solutions 0 (control), 7, 14,21, 28 and 35\% (v/v) methanol by 3 times during growth season of soybean with 12 days intervals on shoot of soybean. Second factor were drought stress condition in two levels 40 and $70 \%$ base of depletion available soil moisture. Results of the experiment indicated that significant differences exist $(p>0.05)$ between sprayed methanol stress levels on measured parameters. Effect of aqueous solution 14, 21 and $28 \%(\mathrm{v} / \mathrm{v})$ methanol on measured parameters was greater than other treatments. Foliar application of 14 and $21 \%(\mathrm{v} / \mathrm{v})$ methanol increased leaf area index, crop growth rate, pod growth rate, leaf area duration, pod yield, seed yield, weight of 1000 kernel, mature pods per plants.

Owen and David [17] studied the impacts of water stress on mitochondrial respiration (R), combining studies at the whole-plant, individual organ, cellular and organelle levels. They noted that water stress almost always inhibited $\mathrm{R}$ in actively growing roots and whole plants. However, in fully expanded, mature leaves the response was more variable, with water stress reducing $\mathrm{R}$ and some showing no change. Importantly, the fact is highlighted that irrespective of whether drought increases or decreases respiration, overall the changes in $\mathrm{R}$ were minor compared with the large decrease in photosynthetic carbon gain in response to drought.

\section{Materials and Methods}

To study "The effect of drought stress on tomato cv. Bombino", an experiment was conducted at Institute of Biotechnology and Genetic Engineering during July 2014. Seeds of tomato cv. Bombino were obtained from Agricultural University Peshawar. The seeds were grown in green house on $26^{\text {th }}$ July 2014 . After three weeks, seedlings were transplanted to large pots where they were maintained and equally watered for healthier growth. As the plants attained a good size (average $23 \mathrm{~cm}$ ) and health, four plants each for controlled and drought condition were selected. The plants in the controlled condition were watered after three days. Withholding water for two weeks imposed drought stress. After that the selected plants were studied for the following parameters.

\section{Relative water content (\%)}

After harvesting, the samples were immediately weighed (Wf). The samples were then oven dried at $70^{\circ} \mathrm{C}$ for 2 days and dry weight were calculated (Wd). Then their average was computed (Wt). Relative Water Content was calculated using the following formula:

Relative Water Content $=($ Wf-Wd $) / \mathrm{Wt} \times 100$

\section{Relative growth rate $(\mathrm{cm})$}

Plant height was recorded by measuring the length of the plant from the soil line to the apical growth at the top before and after stress condition and average was calculated. Relative Growth Rate was calculated using the following formula:

Relative Growth Rate=Final height-initial height/ 2

\section{Relative growth rate (gms)}

Before stress condition four plants from the selected 15 plants sample were harvested and their fresh and dry weights were recorded and their average was calculated as initial reading. While after two weeks of drought stress, final weights both on fresh and dry weight bases were determined. Relative Growth Rate was calculated using the following formula:

Relative Growth Rate (fresh weight basis)=Final fresh wt- initial fresh wt $/ 2$

Relative Growth Rate (dry weight basis)=Final dry. wt-initial dry wt / 2

\section{Proline content $\left(\mu\right.$ moles $\left.\mathbf{g}^{-1}\right)$}

Proline was extracted by grinding $1 \mathrm{~g}$ of frozen plant material in a mortar and pestle. The grinding material was homogenized with $5 \mathrm{ml}$ of $3 \%$ sulfosalicylic acid, the debris were removed by centrifugation at $3000 \mathrm{rpm}$ for 5 minutes. $1 \mathrm{ml}$ of the extract reacted with $2 \mathrm{ml}$ of glacial acetic acid and $2 \mathrm{ml}$ acid ninhydyrin (0.62 ninhydrin warmed to be dissolved in $15 \mathrm{ml}$ glacial acetic acid and $10 \mathrm{ml} 6 \mathrm{M}$ phosphoric acid) for 1 hour at $100^{\circ} \mathrm{C}$, and the reaction was terminated in ice bath. The reaction mixtures were mixed with $10 \mathrm{ml}$ of Toluene. The chromophore containing toluene were aspirated from aqueous phase and warmed up to room temperature for half an hour. The amount of proline was determined with spectrophotometer.

\section{Results and Discussion}

The relative water content, proline content and relative growth rate were studied accordingly and the following results were thus obtained.

\section{Relative water content (\%)}

Water is the most important factor responsible for different plant functions. It is part of living cells of plant. It maintains turger in living cells. It itself is required for the production of new compounds. Being a universal solvent, it is the best source of carrying all the essential metabolites within the plant body. Aside from its importance for biomass water is also essential for plant growth and development. 
It is important for maintaining normal plant body temperature. A plant usually absorbs several times more water than the amount incorporated in cells. Most of it is lost through the stomata during transpiration. The water lost cools the leaf so that it will not be too warm to inactivate the enzymes of photosynthesis and respiration.

When the water supply is disturbed due to drought, all these processes are adversely affected. Due to less availability of water from the outer environment, the water inside the plant body is utilized for transpiration purposes in order to maintain the normal body temperature. By this way the cells tend to loose their turgidity due to loss of water.

It is observed from the mean values of Figure 1 that there is a decrease in the average relative water content of the plant subjected to drought stress as compared to that of controlled conditions. In controlled environment, the mean value of relative water content is $89.28 \%$ while that observed in drought condition is 87.735 which means that about $2 \%$ decrease in the average relative water content of the plants has occurred under stress conditions compared to the controlled situation. The results are in agreement with Nayyar et al. [9] who obtained a decrease amount of relative water content in tomato plants upon stress implementation. A slight variation among the selected plants is also observed due to genetic variances.

\section{Proline content $\left(\mu\right.$ moles $\left.\mathrm{g}^{-1}\right)$}

Plant body is made up of many components i.e. water, carbohydrate,

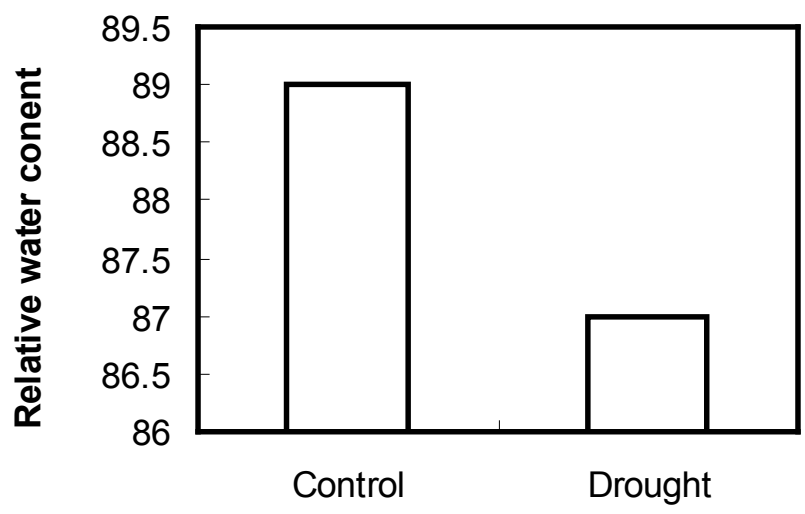

\section{Stress}

Figure 1: The Effect of drought stress on relative water content (\%) of tomato plant.

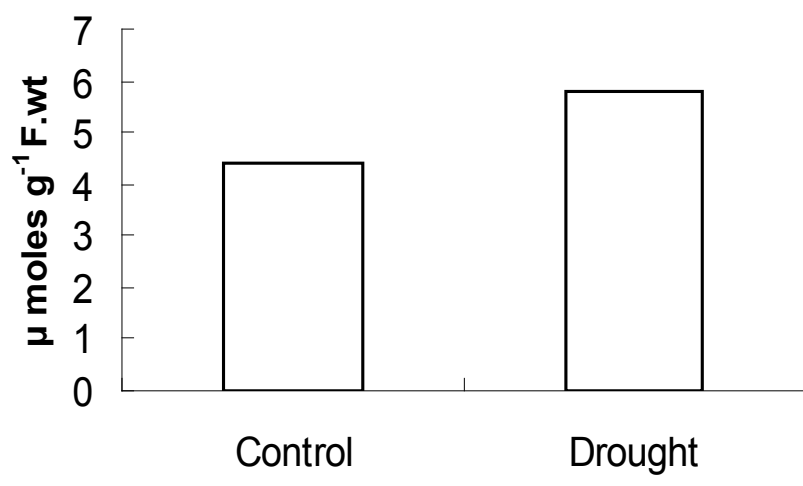

\section{Stress}

Figure 2: The Effect of drought stress on proline ( $\mu$ moles) of tomato plant. amino acid (proline), vitamins, fats etc. All these are inter-connected and depend on each other. These components are in some definite ratio/quantity in relation to each other. Disturbance of any one of them can affect the whole plant mechanism. There is equilibrium of water and proline in plant cells maintaining a good balance. That is most important for normal functioning. When the plant is subjected to water scarcity (drought stress) condition, the amount of water in plant body gradually start to decrease and finally reaches to cellular level where it can disturb the ratio and results in a drastic decline in water quantity leading to an increase of proline level which makes proline in more concentrated form compare to water because drought induce ornithine aminotransferase (OAT) activity which is responsible for proline synthesis. This situation creates a situation of imbalance ratio and rupturing normal cellular activities. Due to drought, less fresh weight is accumulated by the plants which lead to more proline accumulation in concentrated form. It does not mean that this proline may be active in normal body functions. As the solubility of proline is decreased due to low water, the concentrations of proline are increased.

The proline content of tomato plant is shown in the Figure 2. The proline content of the plants increase from normal ratio when they are subjected to stress environment. The value of proline content is 4.4 $\mu$ moles $\mathrm{g}^{-1}$ fresh weight in controlled condition whereas that of plants in drought condition is $5.8 \mu$ moles $\mathrm{g}^{-1}$ fresh weight. This shows that the proline content increases in response to decrease in water availability. Due to decrease in water content (stress condition) the proline content in cell sap increases resulting in high concentration of proline in cell solution. The proline-water ratio was found normal in plants grown in controlled condition. A similar experiment was conducted by Doan and Maurel [7] who found the proline content increases according to the shortage in water availability. Slight changes were also observed among the selected plants which could be referred to genomic variance.

\section{Relative growth rate on plant height basis}

Drought can have major impact on plant growth and development. Plant water stress can be the cause of lower yields and possible crop failure. The effects of plant water stress vary between plant species. Early recognition of water stress symptoms can be critical to maintain the growth of a crop. The most common symptom of plant water stress is wilt. As the plant undergoes water stress, the water pressure inside the leaves decreases and the plant wilts. Drying to a condition of wilt will reduce growth on nearly any plant.

The main consequence of moisture stress is decreased growth and development caused by reduced photosynthesis. Photosynthesis is the process in which plants combine water, carbon dioxide and light to make carbohydrates for energy. Chemical limitations due to reductions in critical photosynthetic components such as water can negatively impact plant growth.

Low water availability can also cause physical limitations in plants. Stomata's are plant cells that control movement of water, carbon dioxide, and oxygen into and out of the plant. During moisture stress, stomata's are closed to conserve water. This also closes the pathway for the exchange of water, carbon dioxide, and oxygen resulting in decrease in photosynthesis. Leaf growth will be affected by moisture stress more than root growth because roots are more able to compensate for moisture stress.

The data pertaining to RGR on plant height basis is given in the Figure 3 which shows that drought stress have effect on the plant height of tomato cv. Bombino. Before stress the average plants height was 


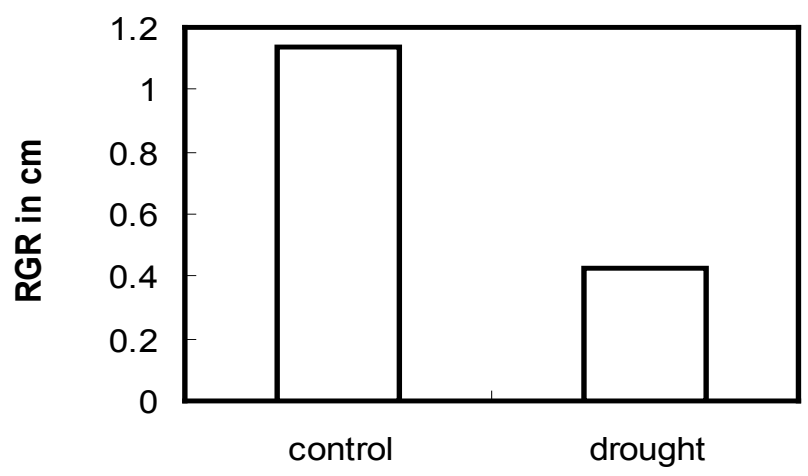

Stress

Figure 3: The Effect of drought stress on height $(\mathrm{cm})$ of tomato plant.

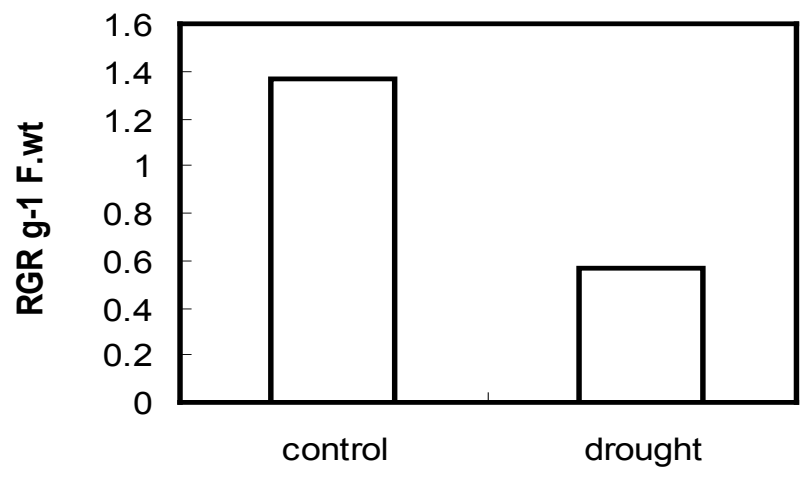

Stress

Figure 4: The Effect of drought stress on fresh weight (gms) of tomato plant.

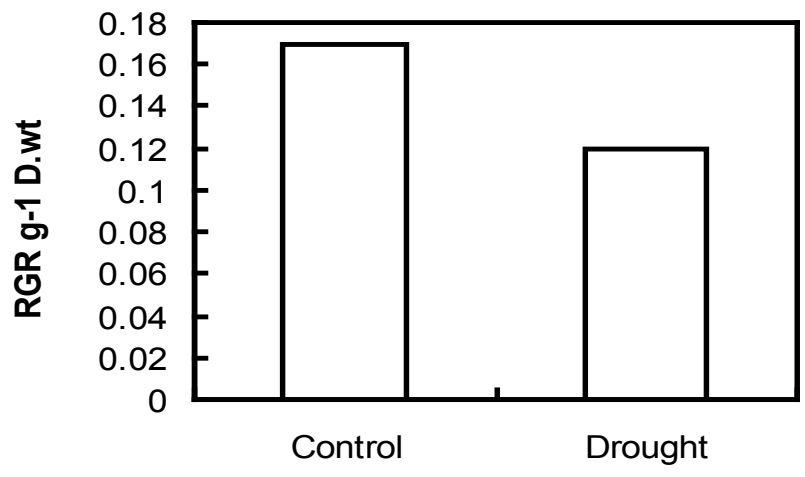

Stress

Figure 5: The Effect of drought stress on dry weight (gms) of tomato plant.

recorded as $23 \mathrm{~cm}$. After withholding water for two weeks the average plants height recorded was $27.5 \mathrm{~cm}$, while in controlled environment the average plants height was $30.5 \mathrm{~cm}$. In control condition, the Relative growth rate week ${ }^{-1}$ was $1.14 \mathrm{~cm}$ and that in drought condition was 0.43 $\mathrm{cm}$. This indicates how the average plants height has decreased when the plants were subjected to drought conditions.

\section{Relative growth rate on fresh weight and dry weight bases}

The relative growth rate of tomato plant is shown in Figures 4 and 5 . The relative growth rate of the plants decreases when they are subjected to stress environment. In controlled condition the relative growth rate week $^{-1}$ on fresh weight bases is $1.37 \mathrm{gm}$ whereas that of plants in drought condition is $0.57 \mathrm{gm}$. The relative growth rate week $\mathrm{k}^{-1}$ on dry weight basis was $0.17 \mathrm{gm}$ in controlled condition while in drought condition 0.12 gm. This shows that the relative growth rate decreased in response to decrease in water availability. Similar results were obtained by Mojtaba et al. [15] in which significant decrease in growth was observed in an experiment conducted on tomato plants exposed to different drought stress conditions .

\section{Summary, Conclusions and Recommendations}

The proposed experiment titled "The effect of drought stress on tomato plant" was conducted in green house at Institution of Biotechnology and Genetic Engineering, KPK Agricultural University Peshawar during July, 2014. The parameters studied were relative water content $(\%)$, relative growth rate $(\mathrm{gm})$ and proline content $\left(\mu\right.$ moles $\left.\mathrm{g}^{-1}\right)$. Tomato plants of selected variety (Bombino) were grown in green house under two different conditions of water availability i-e controlled and drought. The emphasis was lead to the variability of various physiological parameters in stress condition. The relative water content of plant body decline during drought due to less water availability and high transpiration rate. In controlled environment, the mean value of relative water content was $89.28 \%$ while that observed in drought condition was $87.73 \%$. Proline was observed on rise due to continuous decrease in water quantity in cell sap as compared to above solutes. The value of proline content was $4.4 \mu$ moles $\mathrm{g}^{-1}$ fresh weight in controlled condition whereas that the plants in drought condition were $5.8 \mu$ moles $\mathrm{g}^{-1}$ fresh weight. Due to less water, photosynthesis is negatively affected which results in less energy production and finally low growth. In controlled condition the relative growth rate week ${ }^{-1}$ on fresh weight was $1.37 \mathrm{gm}$ whereas that of plant in drought condition was $0.57 \mathrm{gm}$. Along with this, other cellular activities are also disturbed in the same manner. In all, drought stress carries a high variance in plant physiology. The effect of drought stress can also be varied from plant to plant in minute amount.

\section{Conclusions}

The relative water content and growth was drastically reduced while proline content was increased after exposure to drought condition.

\section{Recommendations}

- Regard to the current global situations, there will be scarcity of water. Thus we need to evaluate new varieties of tomatoes which are tolerant to drought stress, because as the result shows, Bombino variety is highly susceptible to drought conditions.

- Crop selection can be a key component when dealing with or anticipating moisture stress. Generalizations about plant groups and how they behave under moisture stress can be used to guide decisions about crop selection for drought and saline conditions.

\section{References}

1. Malik M, Bashir E (1994) Horticulture. National Book Foundation, USA.

2. Ashraf M (1994) Breeding for salinity tolerance in plants. Crit Rev Plant Sci 13: $17-42$.

3. Liming X, Zhu JK (2001) Abiotic stress signal transduction in plants: Molecular and genetic perspectives. Physiologia Plantarum 112: 152-166. 
Citation: Khan SH, Khan A, Litaf U, Shah AS, Khan MA, et al. (2015) Effect of Drought Stress on Tomato cv. Bombino. J Food Process Technol 6: 465. doi:10.4172/2157-7110.1000465

4. Leperen VW, Wilhelm VV, Meeteren V (2003) Distribution of xylem hydraulic resistance in fruiting truss of tomato influenced by water stress. Experimenta Botany 54: 317-324.

5. Tokihiko N, Miki F, Motoaki S, Tomohiko K, Satoshi T, et al. (2003) Toxicity of free proline revealed in an Arabidopsis T-DNA-Tagged mutant deficient in Proline dehydrogenase. Plant and Cell Physio 44: 541-548

6. Gabriella SD, Michela M, Elisabetta O, Giuseppe P, Bray CD, et al. (2004) The histone-like protein $\mathrm{H} 1-\mathrm{S}$ and the response of tomato leaves to water deficit. Experimental Botany 55: 99-109.

7. Doan TL, Maurel C (2005) Aquaporin In a challenging environment: molecular gears for adjusting plant water status. Plant, Cell and Environment 28: 85-96.

8. Hatem ZK, Steppe, Lemeur R (2006) Effect of different level of water stress on leaf water potential, stomatal resistance, protein and chlorophyll content and certain Anti-oxidative enzyme in tomato plants. J Integrative PI Biology 48: $679-685$

9. Nayyar H, Kaur S, Singh KJ, Dhir K, Bains T (2005) Water stress-induce injury to reproductive phase in chickpea: Evaluation of stress sensitivity in wild and cultivated species in relation to abscisic acid and polyamines. J Agron and Crop Sci 191: 450-457.

10. Zhizhong $\mathrm{CH}$, Hairong Z, Youqun W, Xia L, Jian-K Z, et al. (2005) Disruption of the cellulose synthase gene, AtCesA8/IRX1, enhances drought and osmotic stress tolerance in Arabidopsis. Plant J 43: 273-283.
11. Paul VE, Bray A, Elizabeth $A$ (2006) Role of abscisic acid (ABA) and Arabidopsis thaliana ABA-insensitive loci in low water potential-induced $A B A$ and proline accumulation. Experimental Botany 57: 201-212.

12. Achuo EA, Prinsen E, Hofte M (2006) Influence of drought, salt stress and abscisic acid on the resistance of tomato to Botrytis cinerea and Oidium neolycopersici. Plant Pathology 55: 178-186.

13. Dhananjay KS, Peter W, Sale G, Charles K, Pallaghy K, et al. (2000) Phosphorus concentration in the leaves of defoliated white clover affect abscisic acid formation and transpiration in drying soil. New Phytologist 146: 249-259.

14. Hassine AB, Ghanem ME, Bouzid S, Lutts S (2008) An inland and a coasta population of the Mediterranean xero-halophyte species Atriplex halimus L. differ in their ability to accumulate proline and glycinebetaine in response to salinity and water stress. Experimental Botany 59: 1315-1326.

15. Cristina AA, Yvonne MS, Nicole S, Wilhelm G, Lars H (2009) Arabidopsis MSI1 is required for negative regulation of the response to drought Stress. Molecula Plant 2: 675-687.

16. Mirakhori M, Paknejad F, Moradi M, Ardakani F, Zahedi H, et al. (2009) Effect of drought stress and methanol on yield and yield components of soybean. Biochemistry and Biotechnology 5: 162-169.

17. Owen AK, David M (2009) The crucial role of plant mitochondria in orchestrating drought tolerance. Annuals of Botany 103: 581-597. 